\title{
On Preserving the Technogenic Formations of Mining and Smelting Enterprises by Ecologically safe Conservation and Restoration of Landscapes
}

\author{
Antoninova N. Yu. and Shubina L. A
}

Institute of Mining of Ural Branch of RAS, Ekaterinburg, Russia

\section{Abstract}

The mining and smelting industries use various schemes for collecting and treating the surface waters during mining and after its completion, including the use of facilities for deep-treatment of part of the water for reuse in the enterprise. However, the mining sites are often remote from the processing and metallurgical enterprises where these treated waters could be used. Therefore, the problem of effective protection of the environment from negative influence can be solved by application of new technical solutions for conservation/re-cultivation of host and overburden masses moved to the

Corresponding Author:

Shubina L. A

geoeco@igduran.ru

Published: 31 December 2020

Publishing services provided by Knowledge E

(c) Antoninova N. Yu. and Shubina L. A. This article is distributed under the terms of the Creative Commons

Attribution License, which permits unrestricted use and redistribution provided that the original author and source are credited.

Selection and Peer-review under the responsibility of the TECHNOGEN-2019 Conference Committee.

\section{G OPEN ACCESS}

Placement and long-term storage of Mining and Smelting Enterprise's wastes, which are practically unused reserve material base of processing plants, leads to exponential growth of environmental pollution. The consequences of adverse changes in natural components caused by mining and metallurgical enterprises can not be eliminated naturally, and the recovery of ecological balance requires appropriate environmental measures.

The overburden rocks of copper-zinc deposit have included the mining of loose rocks (represented by eluvial-deluvial deposits, folded blocks and rubble of surrounding volcanogenic rocks cemented by clay material) and hard rocks (represented by effusive, extrusive and lime formations, as well as products of their changes). In the process of mining the deposit, except for eluvial-deluvial deposits and hard rocks, the slightly mineralized metasomatic rocks and sulphulite ores were extracted from the near-contact zones and moved out to a separate dump of slightly mineralized rocks. Practically all of the studied territory is covered with a layer of overburden rocky grounds formed as a result of mining the deposit and up to $30-40$ m wide on a number of sites. Ninety per 
cent of the total amount stored on external rock dumps are hard rocks and represented by effusive, extrusive and lime formations and their metasomatic change products. The predominance of sloping surfaces (up to $30^{\circ}$ ) and well permeable ground soils tends to result in landslide movement of material, suffosy, increased atmospheric transfer of small-disperse particles from the surface [1].

Sulphur and pyrite ores and slightly mineralized rocks are temporarily stored in a special warehouse (in various sections), in the amount of 1.1 million $\mathrm{m}^{3}$. In the future, the entire volume of technogenic material should be moved to a borrow excavation and subjected to preservation with insulation from external influences similar to dumps. Thus, the deposit territory for which priority conservation/recultivation measures being proposed does not include borrow excavation.

According to geochemical evaluation criteria, the state of the lithosphere in the area of deposits of non-ferrous metals in content of pollutants in surface water samples corresponds to high degree of pollution. The overburden and host rock dumps formed during mining these deposits pose a significant hazard to the environment, biocenoses, surface and underground waters. Thus, the production wastes stored on the surface result in the chemical water and wind erosion of the rock mass, the formation of water and air dispersion flows, the geochemical pollution of water reservoirs, the formation of geochemical anomalies in soil, snow cover, and vegetation of adjacent territories.

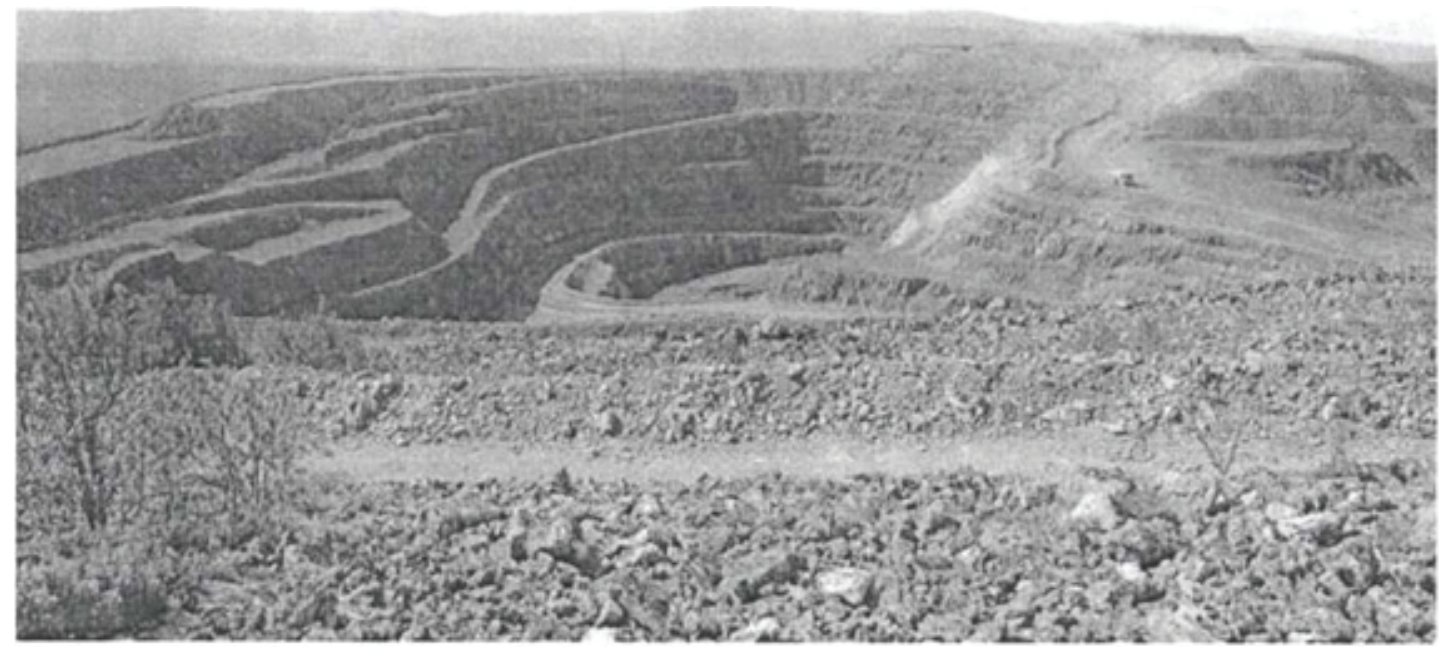

Figure 1: General view of the depleted pit and deposit dumps.

The underspoil and surface waters of non-ferrous metal dumps have different mineralization; the sulphate and heavy metal concentrations vary widely. The chemical composition of underspoil waters during mining the deposit is presented in Table 1.

The underground waters of the area under consideration are not sufficiently protected from surface pollution. Water-bearing materials are overcovered by eluvial-deluvial and eluvial-clay deposits with inclusions of dressing and gravel with average thickness up 
TABLE 1: Characteristics of underspoil waters of the deposit for 2012-2013 [2].

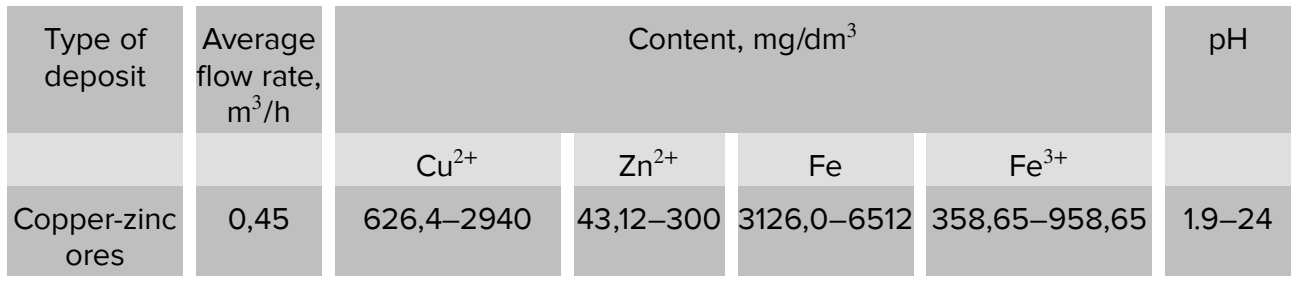

to $10-15 \mathrm{~m}$. There is no soil layer, as well as a layer of loamy-sandy deposits on the area of the deposit dumps.

Formation of soil cover of the territory occurs in conditions of periodically washing water regime. High roughness determines the significant rocky nature of soils. Podsolization prevails on well-drained watershed areas formed by carbonate-free loose rocks. The soil formation occurs on the middle and lower sections of the ridges (slopes) with the participation of the brown earth process, and the sod-forming process develops on the plane feet and aligned surfaces, folded with carbonate rocks.

The soil-forming substrates in this territory are alluvial-deluvial; alluvial (ancient and current); glacial (moraine and fluvioglatial); lake-marsh deposits. The bedrock represented mainly by limestone, is overcovered with heterogeneous red-brown clays, often with limestone debris inclusions. The slit fraction prevails in the mechanical composition. The reaction of the medium is neutral. The amount of absorbed bases is high -59.9 $\mathrm{mg}$ eq/100 g. Calcium prevails in the composition of absorbed bases. These deposits are soil-forming rock for sod-carbonate soils.

Changes in the natural background of the soil cover in the content of metals and metalloids in it consists of the input of polluting elements as a result of atmospheric transfer, as well as by the horizontal migration of them with sub-surface waters.

TABLE 2: Characteristics of contamination of technogenic loamy soils of the deposit territory (total forms).

\begin{tabular}{|c|c|c|c|c|c|c|c|c|} 
No. & $\begin{array}{c}\text { Parameter } \\
\text { name }\end{array}$ & \multicolumn{9}{|c|}{ Value, mg/kg } & & $\begin{array}{c}\text { MAC } \\
\text { (TAC) }\end{array}$ \\
\hline & & Point 1 & Point 2 & Point 3 & Point 4 & Point 5 & Point 6 & \\
\hline 1 & Cadmium & 0,34 & 0,25 & 0,12 & 0,15 & 0,19 & 0,12 & 2 \\
\hline 2 & Zinc & 60,7 & 62,9 & 62 & 48 & 58 & 67,4 & 220 \\
\hline 3 & Nickel & 39,1 & 46,1 & 43,2 & 32,3 & 35,2 & 50 & 80 \\
\hline 4 & Lead & 26 & 30 & 24 & 20 & 20 & 24 & 130 \\
\hline 5 & Arsenic & 20 & 27 & 22,8 & 14,3 & 6,8 & 20,4 & 10 \\
\hline 6 & Copper & 32,2 & 38 & 42,3 & 25,8 & 23,3 & 40,9 & 132 \\
\hline
\end{tabular}

The mining and smelting enterprises use various schemes for collecting and treating the surface waters during mining and after its completion, including the use of facilities for deep-treatment of part of the water for reuse in the enterprise. However, the mining 
sites are often remote from the processing and metallurgical enterprises where these treated waters could be used. Therefore, the problem of effective protection of the environment from negative influence can be solved by application of new technical solutions for conservation/recultivation of host and overburden masses moved to the surface.

The analysis of specific features and conditions characterizing the area of the deposit under consideration gives the basis for the following conclusions in the direction of conservation/recultivation and cost-effective organization of new landscape:

- the design of agricultural recultivation of overburden dumps of the depleted deposit is inefficient due to the lack of reserves of the necessary thickness of the fertile soil layer and the lack of demand for arable land in the region which is not developed by agriculture industry;

- the creation of man-made forest for economic, protective, recreational or sanitaryhygienic purposes is also inefficient in connection with the location of the object of recultivation among continuous natural forests.

Thus, it is reasonable to carry out environmental (sanitary-hygienic) activities on the disturbed lands with elements of forest restoration of the territories of the warehouse of slightly mineralized rocks (after its elimination) by overgrowth with forest species of local flora, as well as regrassing to prevent erosion and weed vegetation.

The development of the copper-pyrite deposit is accompanied by the formation of a geotechnical system, which includes natural and technical components. The conditions of relative stabilization achieved by nature over a long period of time are violated during dumping the mineral waste, and the processes of dispersion of toxic elements are activated, so it should be possible to locate them as much as possible. Therefore, the choice of materials that provide long-term insulating ability of the dump requires to be approached comprehensively, taking into account their economic availability, durability, work in the conditions of contact with aggressive natural and anthropogenic factors. Today, there are a number of technical solutions designed to also reduce costs and timeof carrying out the works at the mining and technical stage of recultivation, while ensuring the appropriate level of stability of inclined recultivated surfaces.

After completion, the rock dumps should form a surface that is convenient for subsequent implementation of measures to restore the floral diversity of the territory.

The surface released from large debris of rocks and industrial structures should be coarsely planned. The thickness of the screening layer of clay soils should be at least $0.5 \mathrm{~m}$. The necessary technique in the formation of the screening layer is compaction of the applied rocks by their layer-by-layer rolling by plain rollers with high specific 
pressure. The technology of formation of horizontal screens can be adopted according to the "Guidelines..." [3]. The thickness of a layer of top soils and potentially rich rocks, sufficient for sowing perennial grass, should be at least $0.15 \mathrm{~m}$. After the formation of the recultivation layer, the finishing planning should be carried out with the creation of a ridge-and-rolling topography perpendicular to the direction of the prevailing winds. The ridge-and-rolling topography is the most favorable for fixing seeds and subsequent growth of woody and shrub vegetation, in accordance with the "Guidelines for the preparation of projects for the reclamation of used disturbed lands and earthing of unproductive lands".

In the formation of the recultivation layer by the above methods it is necessary to regulate the surface waters on the boundaries of elevations and on the surface in order to carry out collection and treatment of waste waters and transfer them to the existing hydrographic network.

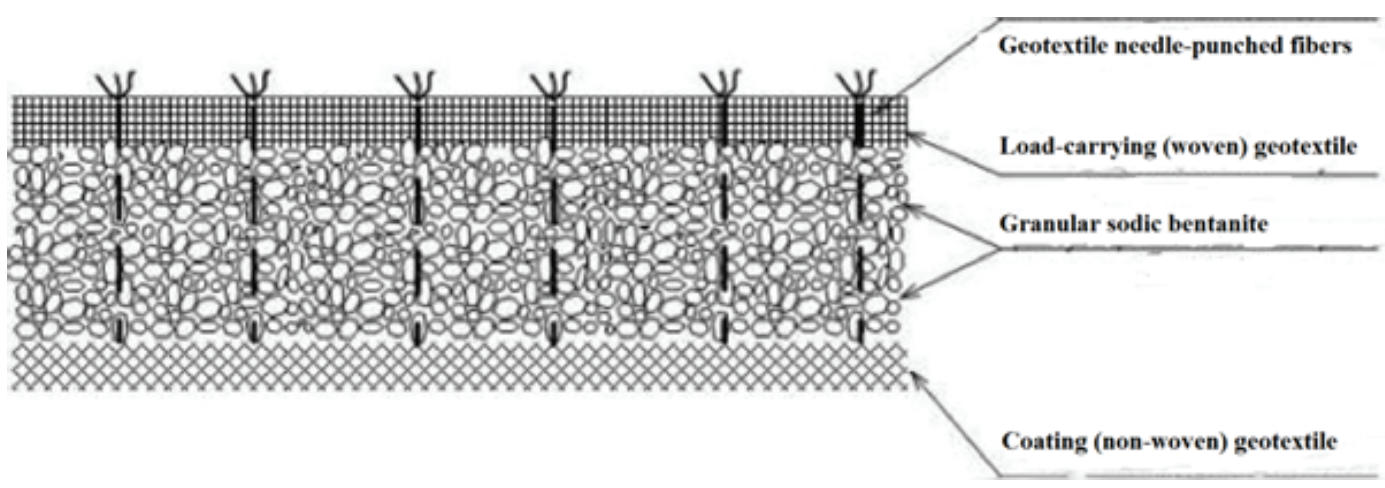

Figure 2: Arrangement of bentonite mat layers.

Sodic bentonite is one of the varieties of clay of natural origin. The principle of bentonite mats is based on the property of sodium bentonite to "swell" and increase in volume (up to 14-16 times) during hydration. This material is used as an anti-filtration screen to protect against penetration of any types of pollutants into the soil, the surface and ground waters. When this process occurs in a confined space, there is a stress state in the structure of the formed gel, due to which the water resistance of the material is achieved. In addition to the above property due to the formation of "bentonite gel" the bentonite mats have a unique ability to "self-heal" in case of mechanical damages, which in most cases are unavoidable during the transport and installation of the material. It should also be noted that the bentomat coating is much lighter and faster in laying than any of the mineral insulations and geomembranes.

The domestic and foreign researches as well as the practice of recultivation of disturbed lands have shown a positive experience in formation of recultivation layer by formation of isolating, capillary breaking and root layers [4-7] with respective thickness of $0.15,0.30$ and $0.8 \mathrm{~m}$. For dumps of the Moscow lignite basin as an effective method 
to form recultivation layer it is proposed to apply a screen of carbonate loam of 0.4$0.6 \mathrm{~m}$ thick on phytotoxic sulfide-containing rocks. In the conditions of arid zone of Kazakhstan it is recommended to make a screen by a layer of rubble or clay of $0.4 \mathrm{~m}$ thick, providing as well the creation of watertight stratum with subsequent application of potentially rich rocks.

In the uppermost layer (in the applied potentially rich rocks or top soils) of the structure formed to insulate the dump grounds and in case of inclusion of even several artificial mineral layers in this structure the dump surface will change quite quickly. Reorganization of soil material begins in the first months and manifests itself in aggregation of organic and soil inherited from the donor soil. For the first few years, the bonding of microaggregates usually leads to the formation of predominantly lumpy macroaggregates which, in turn, by crushing the grass with thin roots acquire a looser and grainier structure that does not prevent the tree seeding.

The process of initial stages of seeding and change of tree vegetation on industrial dumps is similar to natural stages. The factors limiting the development of vegetation cover, along with agrochemical indicators of technogenic soils, are the zone conditions of the territory and the presence of natural sources of seeding in close proximity to the disturbed territory, etc. As shown by long-term research of the Institute of Mining of Ural branch of RAS, the vegetation of overburden dumps is close to the forest vegetation, but the species composition is impoverished, because along with the change in the topography the microclimatic conditions, growing conditions and forest types change.

The forest areas in close proximity to disturbed lands play a decisive role in providing the seeds and natural seeding of disturbed lands and forming forest cenosis on them. As a rule, the pioneer vegetation in this case are broadleaved species, such as birch and asper of different species. This is confirmed by the presence of open birch communities on the lower horizons and at the foot of existing dumps on the territory of the Shemurskoye deposit.

Birches have 10-15 well-developed horizontal roots of the first order, forming a dense network of skeletal, semi-skeletal and suction roots in the upper horizons of the soil. By the age of trees over 25 years the length of horizontal roots of the first order reaches $8.05 \mathrm{~m}$ at the diameter of $13.6 \mathrm{~cm}$. The tap roots of birches in this climatic zone are developed poorly due to sufficient humidity and penetrate deep into the soil to a depth of $50 \mathrm{~cm}$ only to the age of the tree from 27 years and older. Thus, seeding the birch forest on the dumps will not create a significant hazard to disrupt the integrity of the insulating/covering material by wood roots. 
The proposed approach combining the use of insulating geosynthetic materials and the use of the complex of climatically adapted plants allows protecting the land from effects of toxic waste waters, erosion and deflation.

The recommended solutions for the implementation of technical and biological stages of recultivation allow:

- to restore the area seized during dumping the copper-sulphide ore mining wastes;

- to ensure the long-term stability and safety of the recultivated object due to grassing the surface;

- to restore the climatic and water balance of the territory;

- to restore the natural and economic value of the disturbed lands through the agrotechnical methods for creating the natural landscape in the nature for this climatic zone, which will contribute to the conservation of the territory's biodiversity.

The mining and processing enterprises' wastes stored in dumps and tailings are subjected to intensive hypergenesis and change technological properties due to the formation of easily soluble salts of non-ferrous metals, which, as a result of migration, are irretrievably lost for production, but are integrated into natural biogeochemical cycles and lead to irrecoverable distortions in the functioning of ecosystems.

\section{References}

[1] Antoninova, N. Y. and Shubina, L. A. (2017). On Features of Complex Ecological Analysis of Areas Experiencing Local Technogenic Load of Mining and Smelting Enterprises. Ecologiya i Promyshlennost Rossii, issue 2, p. 52.

[2] Ministry of Transport of the Russian Federation. (2013). Recommendations on the Use of Geosynthetic Materials in the Construction and Repair of Highways by. Moscow: ROSAVTODOR.

[3] Orekhova, N. N. (2014). Experimental Comparison of Technologies of Extraction of Copper and Zinc from Underspoil Waters of Copper-Zinc Mining Enterprises. Gorny informatsionno-analitichesky byulleten, issue 10, pp. 2-4.

[4] Adu-Wusu, C. and Yanful, E. K. (2006). Performance of Engineered Test Covers on Acid-Generating Waste Rock at Whistle Mine. Canadian Geotechnical Journal, vol. 43, issue 1, pp. 1-18.

[5] Strzalkowski, R. and Kazmierczak, U. (2019). The Scope of Reclamation Works for Areas after the Exploitation of Rock Raw Materials. Applied Sciences, vol. 9, issue 6, p. 1181. 
[6] Motorina, L. V., et al. (1982). Biological Recultivation of Dumps with Sulfide-Containing Rocks in the Moscow Lignite Basin. Plants and Industrial Environment, issue 9, pp. 44-52.

[7] Komlev, V. N. and Konukhin, V. P. (1995). Complex Experimental Investigation of Materials of Protective Geotechnical Barriers for Radioactive Waste Storage Sites. In Proceedings the International Conference "Use of the Underground Space of the Country to Improve the Safety of Nuclear Power"( October 1992). Apatity: Kola Science Center RAS (Apatity), pp. 97-108. 